\title{
o-7. Studies on the Relationship Between the Muscle Atrophy of the Supraspinatus and the Infraspinatus and the Suprascapular Nerve of the Baseball Players
}

\author{
Tadaatsu Ito, Masayuki Iketani, Katsuhiro Koкubo and \\ Shoichi OBInata \\ Dept. of Orthop. Surg., Nippon Medical School
}

\begin{abstract}
Among a total of two hundred and twenty baseball players seventy-one $(32.2 \%)$ cases showed the muscle atrophy of the supraspinatus and the infraspinatus. Particularly thirty-one $(64.5 \%)$ cases of the forty-eight pitchers showed the muscle atrophy.

On the anatomical investigation of the suprascapular nerve, we found that certain extremes of scapular motion could render the nerve taut and kink it over an edge of the suprascapular foramen. Furthermore using a strain-gage fixing the scapula of the autopsy material, we found that traction applied to the nerve caused tension at the point of the suprascapular foramen at the arm of 90 degrees abduction and internal rotation and the arm into cross body adduction.

As a conclusion pitcher is subject to all disability of the shoulder and his activities predispose him to the development of disability of the shoulder. At the finish of the "iollow through", the arm is cross the chest of the pitcher and the suprascapular nerve is irritated at the suprascapular foramen. This constant activities tends to cause development of the muscle atrophy of the supraspinatus and the infraspinatus.
\end{abstract}

\section{o-8. Peripheral Nerve Regeneration Using Irradiated Homografts}

\author{
Michio Odaka, Toshitsune Shimada Hiroyasu Makino, \\ Kaichi Isono, and Hiroshi SATo \\ Second Surgical Department Chiba University School of Medicine \\ Hideo Matsuzawa \\ National Institute of Radiological Medicine
}

The repair of large defects inn peripheral nerves after injury is one of the most difficult and interesting problem in this field. It is the best method to repair of large defects in peripheral nerve with homograft of the nerve. Recently Bassett and Marmor have reported clinical successful cases using irradiated nerve grafts. We have also started this study co-operating with staffs of the National Institute 